\title{
Association Of Multispecific Red Blood Cell Alloimmunization With HLA-Class II Variants is Related to Mjor RhD Phenotypes
}

\author{
Alena Maluskova ( $\square$ alena.maluskova@fno.cz ) \\ University Hospital Ostrava https://orcid.org/0000-0002-9212-4160 \\ Frantisek Mrazek \\ Univerzita Palackeho v Olomouci Lekarska fakulta
}

Renata Kozelska

Fakultni Nemocnice Ostrava

Martin Koristka

Fakultni Nemocnice Ostrava

\section{Zuzana Cermakova}

Fakultni Nemocnice Ostrava

Research article

Keywords: HLA, red blood cell (RBC) antigens and antibodies (Abs), Rh phenotypes, transfusion therapy.

Posted Date: June 11th, 2020

DOI: https://doi.org/10.21203/rs.3.rs-33800/v1

License: (c) (i) This work is licensed under a Creative Commons Attribution 4.0 International License. Read Full License 


\section{Abstract \\ Background}

It remains unclear why only some patients form alloantibodies against foreign RBC antigens. Transfusion of red blood cell (RBC) products and pregnancy are the most relevant causes of immunization against RBC alloantigens. Here we investigated the relationship between RBC alloantibodies, Rh phenotype, and HLA phenotype among patients with multiple RBC alloantibodies

\section{Methods}

In a group of 124 multi-responders-including both pregnant women and transplant recipients-we analyzed the distribution of HLA-Class II variants in subgroups of multi-responders to RBC alloantigens according to their Rh status.

\section{Results}

As expected, the RhD-negative phenotype was overrepresented in our alloimmunized group (49.2\%) compared to in the general population. Importantly, HLA-DRB1*15 carriers were significantly overrepresented among $\mathrm{D}$-negative multi-responders compared to $\mathrm{D}$-positive multi-responders $(P \mathrm{C}=$ 0.045). Furthermore, the linked HLA-DRB1*13, HLA-DQB1*06, and HLA-DQA $1 * 01$ variants were more frequent in individuals with the DCCee phenotype than in other RhD-positive phenotypes.

\section{Conclusion}

Our present findings showed that RBC multispecific alloimmunization was associated with particular HLA-Class II variants based on Rh status.

\section{Background}

Blood product transfusion is an essential and irreplaceable supportive therapy in many diseases. However, even when the donor and recipient are conventionally matched in terms of ABO (and partly to $\mathrm{RhD}$ and $\mathrm{K}$ ), red blood cell (RBC) product usage can lead to the formation of alloimmune antibodies against other RBC alloantigens. Although such RBC alloimmunization is a serious and frequent complication of transfusion therapy [1], only a minority of individuals who receive RBC transfusion develop alloantibodies [2, 3]. RBC alloimmunization incidence rates range from 18-65\%, and are significantly higher in patients with sickle cell disease or thalassemia compared to the general population [4-8]. 
It is not yet fully understood why only some RBC product recipients form alloantibodies against the foreign donor RBC antigens, but several established risk factors are associated with RBC

alloimmunization, including donor and recipient RBC antigen disparity, recipient genetic factors, and inflammatory state. With regards to immunogenetic factors, several studies have demonstrated an association between the presence of monospecific alloantibodies and particular HLA-DRB1 variants [913]. Moreover, RBC multi-responder status is generally associated with HLA-DRB1*15 variant [13-15], supporting the concept that HLA restriction may play an important role in susceptibility to RBC alloimmunization.

Based on previous findings regarding genetic susceptibility to RBC alloimmunization, in the present study, we focused on patients with multispecific antibody formation, i.e., "multi-responders". Here we investigated the relationship between RBC alloantibodies, Rh phenotype, and HLA phenotype within a group of patients with multiple RBC alloantibodies.

\section{Methods}

\section{Study population}

Residual blood samples were collected from RBC-immunized individuals between March 2014 and December 2015. We performed pre-sampling based on antibody specificities from the Blood Centre database of the University Hospital of Ostrava. The study ultimately enrolled 124 patients with more than one RBC alloantibody ("multi-responders"), i.e., with selected combinations of alloantibodies against Rh (D, C, E, C, e), Kell (K), Kidd ( $\left.\mathrm{Jk}^{\mathrm{b}}, \mathrm{Jk}^{\mathrm{a}}\right)$, and Duffy $\left(\mathrm{Fy}^{\mathrm{a}}\right)$ antigens.

\section{RBC antibody testing techniques}

We identified clinically relevant RBC antibodies by routine indirect antiglobulin testing in a low ionic strength solution using a gel microcolumn hemagglutination technique (DG Gel®; Grifols, Spain) with an 11-cell diagnostic panel of red blood cells (Identisera Diana; Grifols, Spain). We used an in-house adsorption technique to resolve the anti-C+D mixture of antibodies from anti- $G$ in pregnant women.

\section{DNA extraction and HLA genotyping methods}

DNA was isolated from blood samples using a spin column method (High Pure PCR Template Preparation Kit; Roche Diagnostics GmbH, Germany) or an automated technique (Maxwell囚 16 Blood DNA Purification Kit; Promega Corp., WI, USA). After obtaining informed consent from the patients, HLA genotyping was performed. In the cohort of multi-responders, HLA genotyping of the -DRB1 and -DQB1/DQA1 loci was performed by polymerase chain reaction with sequence-specific oligoprobes (PCR-SSO), using Luminex technology with an analysis platform of a microsphere-based assay (LABType ${ }^{\circledR}$ SSO DRB1 and LABType ${ }^{\circledR}$ SSO DQA1/DQB1; One Lambda, CA, USA).

\section{Statistical analyses}


The phenotypic frequencies of the HLA-DRB1, HLA-DQB1, and HLA-DQA1 variants were compared between RhD-positive and RhD-negative patient subgroups, and between RhD-positive patients with the DCCee phenotype and RhD-positive patients with different RhD phenotypes (i.e., DCcee, DCcEe, DccEe, and DccEE). These comparisons were performed using Pearson's test or Fisher's exact test (when there were few patients in a subgroup). We calculated the odds ratio (OR) with a $95 \%$ confidence interval (Cl), and the $P$ value. Nominal $P$ values of $<0.05$ were corrected for multiple comparisons using the Bonferroni method. Between-group differences with corrected $P$ values $(P C)$ of $<0.05$ were considered statistically significant.

\section{Results}

Our heterogeneous cohort included 124 alloimmunized patients (female-to-male [F/M] ratio, 2.76) with at least two RBC alloantibody specificities (multi-responders). In these patients, we detected 19 different RBC antibodies (Table 1). Of the 124 individuals, 72 (69\%; F/M ratio, 2.4) underwent transfusion therapy at the University Hospital of Ostrava (median, 4 units; range, 1-48 units) and were tested within the follow-up period at our department, while 31 patients (F/M ratio, 1.7) with multiple antibody specificities had no transfusion history at our hospital. The cohort included 91 women, of whom 20 (22\%) had alloantibody-complicated pregnancies. The mean age was 66.3 years (range, $42-90$ years) among the 33 males, 69 years (range, 39-91 years) among the 71 females, excluding the pregnant women, who had an average age of 31.9 years (range, $22-43$ years). 
Table 1

Number of individuals, F/M ratio, and RhD phenotype of the subgroups according to the particular antibody combinations in multi-responders $(N=124)$

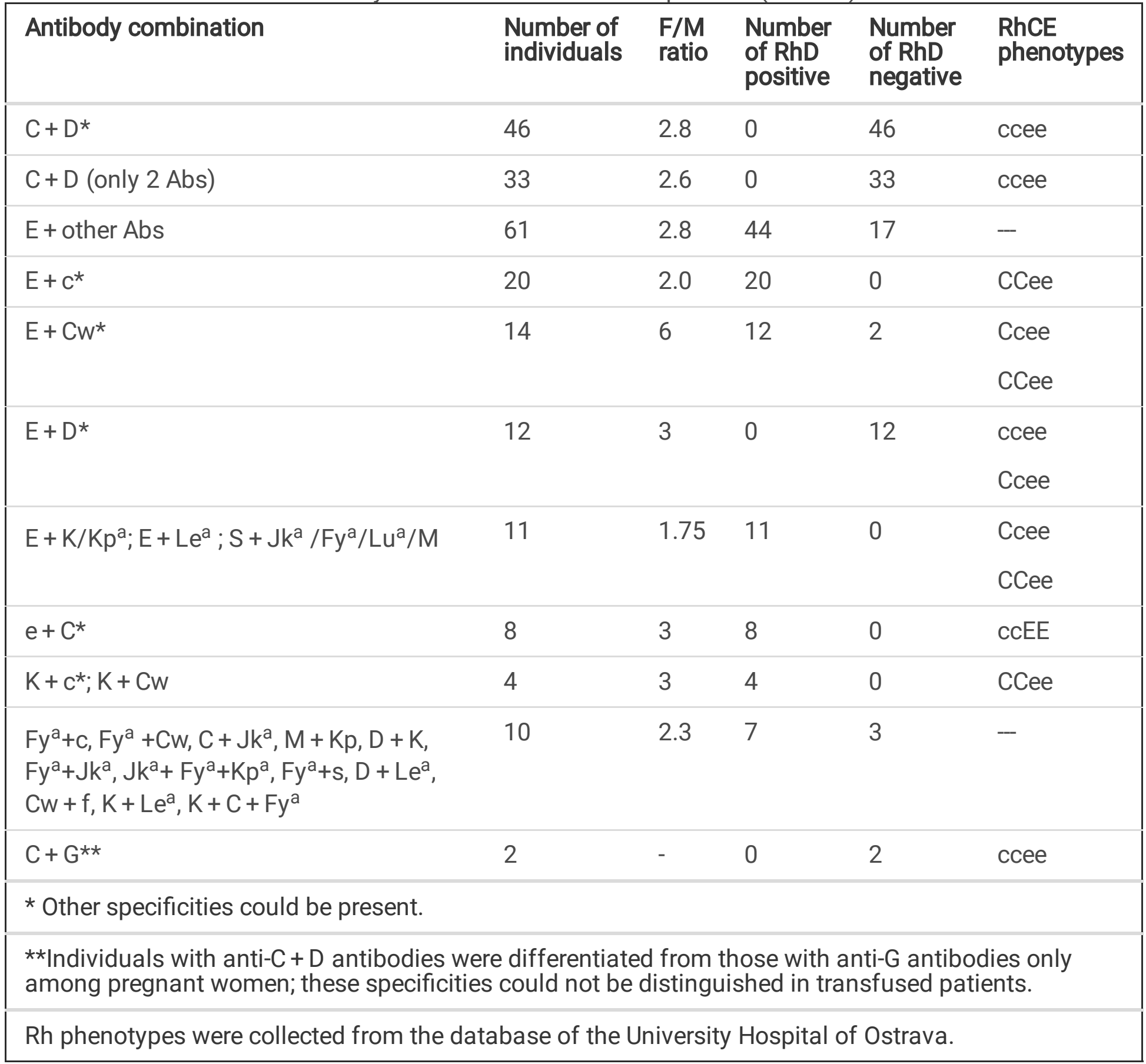

Analysis of multiple RBC alloantibody profiles and RhD phenotypes revealed two main patterns. As expected, antibody combinations including anti-D were associated with a RhD-negative phenotype, while the combinations including anti-E were common for both major RhD phenotypes. However, anti-E was formed by D-negative individuals at a lower frequency than by D-positive individuals ( $27.9 \%$ vs. $72.1 \%)$. Anti-D was more commonly present in combination with some common specificities, including $D+C$ (75.4\%) and $D+E(19.7 \%)$, and much less frequently combined with others, e.g., $D+K$ and $D+L e^{a}(3.3 \%)$. The D-negative group exhibited a high F/M ratio (2.8), necessitating that we consider pregnancymediated RBC alloimmunization, in addition to transfusion. Several antibody combinations were 
apparent only in RhD-positive cases, including E + c (30.2\%), e + C (12.7\%), E + other (non-Rh blood group system) specificities (17.5\%), and $\mathrm{K}+\mathrm{c} / \mathrm{CW} / \mathrm{C}(6.3 \%)$. Other specificities occurred in both RhD phenotypes but predominantly in RhD-positive cases. A combination of $\mathrm{E}+\mathrm{CW}$ antibodies was found in $11.3 \%$ of individuals, and a mixture of non-E and non-D antibodies occurred in $10.5 \%$ of cases.

The RhD-negative phenotype was observed in $49.2 \%$ of multi-responders, and the ratio of RhD-positive to RhD-negative individuals was 1.07 among females and 0.94 among males. As expected, the combination of anti-C $+D$ antibodies was found only in D-negative individuals ( $F / M$ ratio, 2.6, including two pregnant women). In contrast, the combination of anti-E + other specificities (any of $\mathrm{C} / \mathrm{CW} / \mathrm{C} / \mathrm{D} / \mathrm{K} / \mathrm{Le}^{\mathrm{a}} / \mathrm{Fy}^{\mathrm{a}} / \mathrm{Jk}^{\mathrm{a}} / \mathrm{Jk}^{\mathrm{b}} / \mathrm{M}$, etc.), occurred in patients with both major RhD phenotypes. The frequency of individuals carrying anti- $C+D$ antibodies reached $75.4 \%$, representing the most common alloantibody combination in RhD-negative individuals. The combination of anti-E + other specificities was detected in 61 cases (49.2\%) among all 124 multi-responders, and in 44 cases (69.8\%) among the 63 RhD-positive individuals (F/M ratio, 2.8, including 10 pregnant females). Table 1 shows all observed RBC antibody combinations.

Further exploration of a subgroup of 20 pregnant women with multiple RBC alloantibodies revealed 8 $\mathrm{RhD}$-negative and $12 \mathrm{RhD}$-positive phenotypes. Among pregnant women, the anti- $\mathrm{E}+\mathrm{C}$ antibody combination was detected in 5 cases, anti-E + CW in 4 cases, anti-D $+E, C+G, C+D$ in 2 cases each, and other combinations in 1 case each (i.e., $E+L e^{a}, D+L e^{a}, C+E$, and $c+K$ ).

The proportion of the RhD-negative phenotype was substantially higher in our group of multi-responders (49.2\%) compared to that reported in Caucasian populations (range, 12-18\%) and HLA-DRB1*15 has previously been described as susceptibility marker for RBC multiple alloimmunization. Therefore, we performed a subanalysis of the HLA-Class II variants according to the patients' RhD status. Importantly, in our group of multi-responders, we found a significantly higher phenotypic frequency (proportion of carriers) of HLA-DRB1*15 in D-negative patients than in D-positive individuals $(P C=0.045)$. This finding was in agreement with analyses of the relationship between HLA-DRB1 and combinations of alloantibodies, which revealed 28 (60.9\%) DRB1*15 carriers among 46 individuals forming anti-C + D alloantibodies, but only 3 DRB1*15-positive subjects exhibiting other alloantibody combinations. Table 2 presents the phenotypic frequencies of HLA-DRB1, HLA-DQB1, and HLA-DQA1 in RhD-negative and RhDpositive multi-responders. 
Table 2

Comparisons of phenotypic frequencies of HLA-DRB1, HLA-DQB1, and HLA-DQA1 variants among the RhD-negative $(N=61)$ and RhD-positive $(N=63)$ multi-responders

\begin{tabular}{|c|c|c|c|c|c|c|}
\hline $\begin{array}{l}\text { Allelic } \\
\text { groups }\end{array}$ & $\begin{array}{l}\text { Percentage of RhD } \\
\text { negative }\end{array}$ & $\begin{array}{l}\text { Percentage of RhD } \\
\text { positive }\end{array}$ & $\begin{array}{l}P \\
\text { value }\end{array}$ & OR & $\begin{array}{l}95 \% \\
\mathrm{Cl}\end{array}$ & $\begin{array}{l}P c \\
\text { value }\end{array}$ \\
\hline DRB1*01 & 22.9 & 22.2 & 1.0 & & & \\
\hline DRB $1 * 03$ & 19.7 & 28.6 & 0.2 & & & \\
\hline DRB $1 * 04$ & 11.5 & 22.2 & 0.1 & & & \\
\hline DRB1*07 & 29.5 & 30.2 & 1.0 & & & \\
\hline DRB $1 * 08$ & 3.3 & 3.2 & 1.0 & & & \\
\hline DRB1*09 & 3.3 & 0 & 0.8 & & & \\
\hline DRB1*10 & 3.3 & 1.6 & 1.0 & & & \\
\hline DRB $1 * 11$ & 21.3 & 20.6 & 1.0 & & & \\
\hline DRB $1 * 12$ & 3.3 & 1.6 & 1.0 & & & \\
\hline DRB $1 * 13$ & 16.4 & 28.6 & 0.1 & & & \\
\hline DRB $1 * 14$ & 1.6 & 6.3 & 0.2 & & & \\
\hline DRB1*15 & 50.8 & 25.4 & 0.0035 & 3.04 & $\begin{array}{l}1.4- \\
6.5\end{array}$ & 0.045 \\
\hline DRB1*16 & 1.6 & 7.9 & 0.1 & & & \\
\hline $\mathrm{DQB} 1 * 02$ & 42.6 & 46.0 & 0.7 & & & \\
\hline $\mathrm{DQB} 1 * 03$ & 39.3 & 47.6 & 0.4 & & & \\
\hline $\mathrm{DQB} 1 * 04$ & 1.6 & 1.6 & 1.0 & & & \\
\hline DQB1*05 & 32.8 & 39.7 & 0.4 & & & \\
\hline DQB1*06 & 55.7 & 44.4 & 0.2 & & & \\
\hline DQA $1 * 01$ & 75.4 & 74.6 & 1.0 & & & \\
\hline $\mathrm{DQA} 1 * 02$ & 29.5 & 30.2 & 1.0 & & & \\
\hline $\mathrm{DQA} 1 * 03$ & 14.7 & 22.2 & 0.3 & & & \\
\hline DQA1*04 & 3.3 & 1.6 & 0.6 & & & \\
\hline DQA1*05 & 37.7 & 50.8 & 1.1 & & & \\
\hline DQA $1 * 06$ & 0 & 1.6 & 0.2 & & & \\
\hline
\end{tabular}


Among the D-positive multi-responders, we performed a more detailed investigation of the DCCee phenotype, which was the most prevalent phenotype among D-positive cases (52.4\%; F/M ratio, 2.0). Notably, the individuals with this phenotype could theoretically form combinations of anti-E $+\mathrm{C}$ alloantibodies. In fact, among 33 patients with the DCCee phenotype, 20 cases (60.6\%) formed the anti-E $+\mathrm{c}$ combination. We then compared the distribution of HLA-Class II variants between patients with the DCCee phenotype and all other RhD-positive phenotypes. Individuals with the DCCee phenotype exhibited a significantly higher frequency of HLA-DRB1*13 $(P C=0.015)$, and further association of HLA alleles in linkage disequilibrium (HLA-DQB1*06, $P C=0.01 ; \mathrm{HLA}-\mathrm{DQA} 1 * 01, P \mathrm{C}=0.002)$ (Table 3 ). 
Table 3

Comparisons of phenotypic frequencies of HLA-DRB1, HLA-DQB1, and HLA-DQA1 variants among multiresponders with the DCCee phenotype $(N=33)$ and all other RhD-positive phenotypes $(N=30)$

\begin{tabular}{|c|c|c|c|c|c|c|}
\hline $\begin{array}{l}\text { Allelic } \\
\text { groups }\end{array}$ & $\begin{array}{l}\text { Percentage of Rh } \\
\text { DCCee phenotype }\end{array}$ & $\begin{array}{l}\text { Percentage of all other } \\
\mathrm{RhD}(+) \text { phenotypes }\end{array}$ & $\begin{array}{l}P \\
\text { value }\end{array}$ & OR & $\begin{array}{l}95 \% \\
\mathrm{Cl}\end{array}$ & $\begin{array}{l}P c \\
\text { value }\end{array}$ \\
\hline DRB1*01 & 24.2 & 20.0 & 0.8 & & & \\
\hline DRB1*03 & 30.3 & 26.7 & 0.8 & & & \\
\hline DRB1*04 & 9.1 & 36.7 & 0.013 & 0.17 & $\begin{array}{l}0.04- \\
0.7\end{array}$ & NS \\
\hline DRB1*07 & 24.2 & 36.7 & 0.4 & & & \\
\hline DRB1*08 & 0 & 6.7 & 0.2 & & & \\
\hline DRB1*09 & 0 & 0 & 1.0 & & & \\
\hline DRB1*10 & 0 & 3.3 & 0.5 & & & \\
\hline DRB1*11 & 21.2 & 6.7 & 0.2 & & & \\
\hline DRB1*12 & 0 & 3.3 & 0.1 & & & \\
\hline DRB1*13 & 45.5 & 3.3 & 0.0001 & 24 & $\begin{array}{l}2.9- \\
199\end{array}$ & 0.015 \\
\hline DRB1*14 & 3.0 & 10.0 & 0.3 & & & \\
\hline DRB1*15 & 27.3 & 23.3 & 0.8 & & & \\
\hline DRB1*16 & 9.1 & 6.7 & 0.4 & & & \\
\hline DQB1*02 & 42.4 & 50.0 & 0.8 & & & \\
\hline DQB1*03 & 39.4 & 56.7 & 0.3 & & & \\
\hline DQB1*04 & 0 & 3.3 & 0.5 & & & \\
\hline DQB1*05 & 39.4 & 40.0 & 1.0 & & & \\
\hline DQB1*06 & 63.6 & 23.3 & 0.002 & 5.8 & $\begin{array}{l}1.9- \\
17.3\end{array}$ & 0.01 \\
\hline DQA1*01 & 93.9 & 53.3 & 0.0003 & 13.5 & $\begin{array}{l}2.7- \\
67.2\end{array}$ & 0.002 \\
\hline $\mathrm{DQA} 1 * 02$ & 24.2 & 36.7 & 0.5 & & & \\
\hline DQA $1 * 03$ & 9.1 & 36.7 & 0.014 & 0.17 & $\begin{array}{l}0.04- \\
0.7\end{array}$ & NS \\
\hline DQA $1 * 04$ & 0 & 3.3 & 0.5 & & & \\
\hline
\end{tabular}

${ }^{a} P$ value of $<0.05$ is considered significant. 


\begin{tabular}{|c|c|c|c|c|c|c|}
\hline $\begin{array}{l}\text { Allelic } \\
\text { groups }\end{array}$ & $\begin{array}{l}\text { Percentage of Rh } \\
\text { DCCee phenotype }\end{array}$ & $\begin{array}{l}\text { Percentage of all other } \\
\mathrm{RhD}(+) \text { phenotypes }\end{array}$ & $\begin{array}{l}P \\
\text { value }\end{array}$ & OR & $\begin{array}{l}95 \% \\
\mathrm{Cl}\end{array}$ & $\begin{array}{l}P c \\
\text { value }\end{array}$ \\
\hline DQA $1 * 05$ & 54.5 & 46.7 & 0.6 & & & \\
\hline DQA $1 * 06$ & 0 & 3.3 & 0.5 & & & \\
\hline
\end{tabular}

\section{Discussion}

In this study, we investigated the distribution of HLA-Class II variants within subgroups of multiresponders to RBC alloantigens, with the aim of elucidating associations between HLA-Class II alleles, Rh phenotypes, and RBC alloimmunization. In previous studies, HLA-DRB1*15 has been associated with multiple RBC antibody responsiveness [13-15]. Here we found that the DRB1*15 variant was twice as frequent in multi-responders with the RhD-negative phenotype as in RhD-positive multi-responders. In other words, it appears that DRB1*15 was associated with multiple alloimmunization (namely anti-C +D), particularly among RhD-negative individuals. Additionally, HLA-DRB $1 * 13$ and the variants in LD with DRB $1 * 13$ (namely HLA-DQB $1 * 06$ and HLA-DQA $1 * 01$ ) were associated with the DCCee phenotype, but not with other RhD phenotypes (i.e., DCcee, DCcEe, DccEe, and DccEE).

In this analysis, we applied a new approach for stratifying the genetic risk for multiple alloimmunization conferred by HLA variants with the implementation of major RBC phenotypes (antigens), since an absence of certain RBC antigen(s) represents a necessary condition for the patients to be immunized against such antigen(s) and to develop alloantibodies. These findings are in concordance with our recent study in which we found that the DRB $1 * 15$ allele was associated with $C+D$ alloantibodies (in Rhccee phenotypes), and the HLA-DRB $1 * 13$ allele (HLA-DQB $1 * 06$ and HLA-DQA1*01) was associated with $E+C$ alloantibodies (in DCCee phenotypes) [14].

Multiple antibody formation seems to be less dependent on the presence of antigen-specific HLA-Class II restriction genes, and more dependent on the immunization to a first and often single antibody. Anti-E immunization is strongly associated with $\mathrm{DRB} 1 * 09$ [13], but the high proportion of anti-E responders is disproportional to the low frequencies of DRB $1 * 09$ among Caucasoids $(\sim 1 \%)$. Our group of multiresponders included 112 individuals (90.3\%) negative for RhE antigen (ratio of RhD-positive to RhDnegative, 0.84 ), and this group could be immunized by allogeneic RhE antigen and form anti-E antibodies. In fact, we found anti-E antibodies (together with other specificities) in 61 cases (54.5\%), suggesting that anti-E immunization was a frequent complication of transfusion in both RhD groups. Therefore, we additionally analyzed the distribution of HLA-DRB1 variants according to the RhE-positive and RhEnegative phenotypes. However, we found no significant changes in the distribution of HLA-Class II variants between the RhE-negative and RhE-positive cases, possibly due to the small size of the RhEpositive subgroup. 
Long-term evidence shows that patients with the RhD-negative phenotype are obviously more prone to RBC alloimmunization. In a recent report from the large Recipient Epidemiology and Donor Evaluation Study (REDS-III), the proportion of RBC alloimmunized patients was $45 \%$ higher among RhD-negative patients than in RhD-positive patients [16]. This finding is in agreement with the higher frequency of RhDnegative phenotypes (49.2\%) among the multi-responders in our study. Overall, accumulating evidence indicates that transfused patients with the RhD-negative phenotype carry a higher risk of developing multispecific RBC alloantibodies.

With regards to the previous reports that HLA-DRB1*15 confers susceptibility to RBC alloimmunization, Sippert et al. compared alloimmunized and non-alloimmunized patients, and identified a significant relationship between Rh alloimmunization and DRB1*15 [17]. Similarly, Moritz et al. reported that HLADRB $1 * 15$ is associated with increased risk of Rh alloimmunization [18]. Several studies have demonstrated that HLA-DRB $1 * 15$ is frequently present in multiple RBC antibody responders, and may define a high-responding phenotype [13-15]. Moreover, HLA-DRB $1 * 15$ is reportedly associated with development of antibodies against multiple HLA antigens [15], autoantibody formation, and even susceptibility to autoimmune diseases $[19,20]$. Despite growing data supporting a relationship between HLA and RBC alloimmunization, the exact mechanism underlying the association between DRB $1 * 15$ and immunization against multiple alloantigens is unknown. Some authors speculate that these findings should not be considered evidence of more efficient antigen presentation, but rather indications that DRB $1 * 15$ is part of a susceptible and immune response "amplifier" haplotype, e.g., for certain cytokine profiles $[15,21]$.

\section{Conclusions}

In conclusion, our present results suggest that the carriage of HLA-DRB1*15 in the RhD-negative phenotype, and of HLA-DRB1*13 (together with DQB1*06 and DQA1*01) in the RhDCCee phenotype, may further increase susceptibility to multi-responsiveness to RBC alloantigens. Once independently verified, these findings may contribute to the identification of patients at higher risk of multiple RBC alloimmunization. For such patients, extended RBC antigen matching ( $D$ and $E$ antigens) could be considered, especially in transfusion-dependent D-negative patients possessing HLA-DRB1* 15 and/or those patients who are E-negative with the HLA-DRB1*13 variant.

\section{Abbreviations}

\section{HLA}

Human leukocyte antigens

RBC

Red blood cell

Abs

Antibodies

NS 
not significant

$\mathbf{N}$

number

\section{Declarations}

\section{Ethics approval and consent to participate}

This study was approved by the Ethics Committee of the University Hospital of Ostrava (approval no. 382/2014). All participants signed an informed consent form prior to enrolment into the study.

\section{Consent for publication}

Not applicable.

\section{Availability of data and materials}

The datasets used and/or analysed during the current study are available from the corresponding author on reasonable request.

\section{Competing interests}

The authors declare that they have no competing interests.

\section{Funding}

This study was supported by institutional grants from University Hospital Ostrava (RVO-FNOs/2014) and Palacky University Olomouc (IGA_LF_2020_016).

\section{Acknowledgements}

We thank our colleagues from the University Hospital Ostrava Blood Centre for their help with collection of samples for this project.

\section{Author contribution}

AM designed the study, carried out genotyping and data analysis, wrote paper; RK assisted with laboratory experiments; FM assisted with analysis and interpretation of the data and reviewed the manuscript draft. MK, ZC consulted of clinical characteristics of enrolled subjects.

\section{References}

1. Davenport RD: Pathophysiology of hemolytic transfusion reactions. Semin Hemato/ 2005; 42:165168. 
2. Higgins JM, Sloan SR: Stochastic modeling of human RBC alloimmunization: evidence for a distinct population of immunologic responders. Blood 2008; 112:2546-2553.

3. Zalpuri S, Zwaginga JJ, le Cessie S, et al. Redblood-cell alloimmunization and number of red bloodcell transfusions. Vox Sang 2012; 102:144-149.

4. Drasar $\mathrm{E}$, Igbineweka $\mathrm{N}$, Vasavda N, et al. Blood transfusion usage among adults with sickle cell disease - A single institution experience over ten years. Br J Haematol 2011; 152:766-770.

5. Tormey CA, Fisk J, Stack G: Red blood cell alloantibody frequency, specificity, and properties in a population of male military veterans. Transfusion 2008; 48:2069-2076.

6. Yazdanbakhsh K, Ware RE, Noizat-Pirenne F. Red blood cell alloimmunization in sickle cell disease: Pathophysiology, risk factors, and transfusion management. Blood 2012; 120:528-537.

7. Ameen R, Al-Shemmari S, Al-Humood S, et al.: RBC alloimmunization and autoimmunization among transfusion-dependent Arab thalassemia patients. Transfusion 2003; 43:1604-1610.

8. Wang LY, Liang DC, Liu HC, et al.: Alloimmunization among patients with transfusion-dependent thalassemia in Taiwan. Transfus Med 2006; 16:200-203.

9. Reviron D, Dettori I, Ferrera V, et al.: HLA-DRB1 alleles and Jk(a) immunization. Transfusion 2005; 45(6):956-9.

10. Noizat-Pirenne F, Tournamille $C$, Bierling $P$, et al.: Relative immunogenicity of Fya and $\mathrm{K}$ antigens in a Caucasian population, based on HLA class II restriction analysis. Transfusion 2006; 46:1328-1333.

11. Picard C, Frassati $C$, Basire A, et al.: Positive association of DRB $1 * 04$ and DRB $1 * 15$ alleles with Fya immunization in a Southern European population. Transfusion 2009; 49(11):2412-7.

12. Chiaroni J, Dettori I, Ferrera V, et al.: HLA-DRB1 polymorphism is associated with Kell immunisation. Br J Haematol 2006; 132(3):374-8.

13. Schonewille H, Doxiadis IIN, Levering WHBM, et al.: HLA-DRB1 associations in individuals with single and multiple clinically relevant red blood cell antibodies. Transfusion 2014; 54:1971-78.

14. Maluskova A, Mrazek F, Pauliskova, et al.: Association of HLA-DRB1 and HLA-DQB1 with red-bloodcell alloimmunization in the Czech population. Vox Sang 2017; 112: 156-162.

15. Verduin EP, Brand A, van de Watering LM, et al.: The HLA-DRB $1 * 15$ phenotype is associated with multiple red blood cell and HLA antibody responsiveness. Transfusion 2016; 56:1849-1856.

16. Karafin MS, Westlake M, Hauser RG, Tormey CA, Norris PJ, Roubinian NH, Wu Y, Triulzi DJ, Kleinman S, Hendrickson JE; NHLBI Recipient Epidemiology and Donor Evaluation Study-III (REDS-III). Risk factors for red blood cell alloimmunization in the Recipient Epidemiology and Donor Evaluation Study (REDS-III) database. Br J Haematol. 2018 Jun;181(5):672-681.

17. Sippert EA, Visentainer JEL, Alves HV, et al. Red blood cell alloimmunization in patients with sickle cell disease: correlation with HLA and cytokine gene polymorphisms. Transfusion 2017; 57:379-389.

18. Moritz E, Souza CP, Cruz B, et al. HLA-DRB1*12 and HLADRB1*15 are associated with antibody response to RHD antigen in Brazilians. Vox Sang 2015;109 Suppl.1:376. 
19. Voorter $C E$, Drent $M$, van den Berg-Loonen EM. Severe pulmonary sarcoidosis is strongly associated with the haplotype HLA-DQB1*0602-DRB1*150101. Hum Immunol 2005;66:826-35.

20. Zhang Q, Lin CY, Dong Q, et al. Relationship between HLADRB1 polymorphism and susceptibility or resistance to multiple sclerosis in Caucasians: a meta-analysis of non-family based studies. Autoimmun Rev 2011;10:474-81.

21. Zota V, Nemirovsky A, Baron R, et al. HLA-DR alleles in amyloid beta-peptide autoimmunity: a highly immunogenic role for the DRB1*1501 allele. J Immuno/ 2009;183:3522-30. 